\title{
Mathematical Model of Suspension Seat-Person Exposed to Vertical Vibration for Off-Road Vehicles
}

\author{
S. Aisyah Adam ${ }^{1}$, N. A. Abdul Jalil ${ }^{1 *}$, K. A. Md Razali ${ }^{1}$, Y. G. Ng ${ }^{1}$ \\ and M. F. Aladdin ${ }^{2}$ \\ ${ }^{1}$ Sound and Vibration Research Group, \\ Department of Mechanical and Manufacturing Engineering, Faculty of Engineering, \\ Universiti Putra Malaysia (UPM), 43400 UPM Serdang, Selangor, Malaysia \\ *Email: nawalaswan@upm.edu.my \\ Phone: +60389466336; Fax: +60386567122 \\ ${ }^{2}$ School of Engineering, Taylor's University Malaysia, Jalan Taylor's, \\ 47500, Subang Jaya, Selangor, Malaysia
}

\begin{abstract}
Off-road drivers are exposed to a high magnitude of vibration at low frequency (0.5$25 \mathrm{~Hz}$ ), that can cause harm and possibly attribute to musculoskeletal disorder, particularly low-back pain. The suspension seat is commonly used on an off-road condition to isolate the vibration transmitted to the human body. Nevertheless, the suspension seat modelling that incorporates the human body is still scarce. The objective of this study is to develop a mathematical modelling to represent the suspension seatperson for off-road vehicles. This paper presents a three degrees-of-freedom lumped parameter model. A curve-fitting method is used for parameter identification, which includes the constraint variable function (fmincon()) from the optimisation toolbox of MATLAB(R2017a). The model parameters are optimised using experimentally measured of suspension seat transmissibility. It was found that the model provides a reasonable fit to the measured suspension seat transmissibility at the first peak of resonance frequency, around 2-3 Hz. The results of the study suggested that the human body forms a coupled system with the suspension seat and thus affects the overall performance of the suspension system. As a conclusion, the influence of the human body should not be ignored in the modelling, and a three-degrees degree-of-freedom lumped parameter model provides a better prediction of suspension seat transmissibility. This proposed model is recommended to predict vibration transmissibility for off-road suspension seat.
\end{abstract}

Keywords: lumped parameter model; seat-person suspension model; suspension seat; transmissibility; vibration isolation system.

\section{INTRODUCTION}

Drivers may feel uncomfortable from the exposure to a low frequency of vibrations transmitted to the body from the seat. Road condition such as rough track and speed of vehicles may increase the level of exposure to whole-body vibration $[1,2]$. Therefore, the isolation system is important for drivers to protect the body from excessive exposure to vibration, especially on the off-road condition. The seat cushion can isolate vibration at a low magnitude, but at higher magnitudes, the suspension seat is necessary to attenuate excessive vibration and shock from being transmitted to the body. 
A suspension seat can be designed to reduce the impact of vibration and shock to the human body [3]. The efficiency of a suspension seat depends on (i) the input vibration at the seat base, (ii) seat transmissibility, and (iii) sensitivity of the human body to the input vibration on the seat surface. The input vibration refers to the excitation sources, such as road roughness, engine, tyres and dynamic working load. The most common way to analyse the characteristics of the suspension seat is to measure its transmissibility.

Seat transmissibility is the ratio between vibrations on the seat surface to the seat base. The characteristics of the seat and the human body are both important. The seat and the human body can form a coupled system that can be affected by each other $[4,5]$. Thus, in order to predict the performance of the suspension seat, it is essential to include human responses in the model as well.

Modelling the suspension seat is necessary to develop an improved suspension seat system $[6,7]$. One of the most commonly developed is the lumped-parameter model [8-11]. Gunston has compared 'Bouc-Wen' and the lumped parameter model to assess a suspension seat's dynamic performance [12]. It was found that the lumped parameter model was preferable for the improvement of overall suspension seat design, while 'Bouc-Wen' was useful for optimisation of individual parts of the suspension seat.

Stein developed a lumped parameter model to predict vibration transmission of the suspension seat with a variable damper, commonly found in the rail transport [13]. However, the findings concluded that using inert mass was a better suit compared to using ISO 5982 and DIN 45676 models [14, 15]. Some studies used the finite element for modelling of car seats and for predicting vibration transmissibility [16-17]. Even though modelling of the coupled seat-human body has been a great interest for the past years, there are not many studies involving a suspension system (cushion and suspension seat) that couples with the human body. Various models of seat transmissibility concentrated on the car seat and not the suspension seat used for off-road conditions.

Standards have proposed to test seat transmissibility by using the rigid mass [18]. Nevertheless, the role of the human body cannot be neglected as the dynamic responses of the human body affect the seat dynamic characteristics, and vice versa. Thus, a suspension seat-person model is essential to investigate and predict the dynamic performance of suspension seat when exposed to vibration. The objective of the present study was to propose a mathematical model for a suspension seat-person system to predict seat transmissibility of suspension seat used in off-road conditions. The model is expected to assist seat manufacturer in optimising suspension seat performance.

\section{METHODOLOGY}

\section{Experimental Measurement}

ISO 7096 [18] provides a guideline for laboratory measurement for suspension seat for off-road conditions. Since this study focuses on off-road suspension seat, the seat transmissibility measured by Qiu was used as a reference to calibrate the model [19]. In the study, a suspension seat of a motor grader was used to study the dynamic characteristics. Three categories of body weight were investigated representing light, medium, and heavyweight subjects, consistent with the requirements of the standard [18].

Subjects were exposed to $1.0 \mathrm{~m} / \mathrm{s}^{2}$ r.m.s random vibration in a vertical direction, with the frequency range of $0.5-25 \mathrm{~Hz}$ for 120 -second. The experiment was conducted with the subjects sitting on a suspension seat that was secured on top of a hydraulic simulator. One accelerometer was secured at the seat base and an SIT pad was positioned 
on the suspension seat to measure its vibration. Figure 1 shows the schematic diagram of the experimental setup.

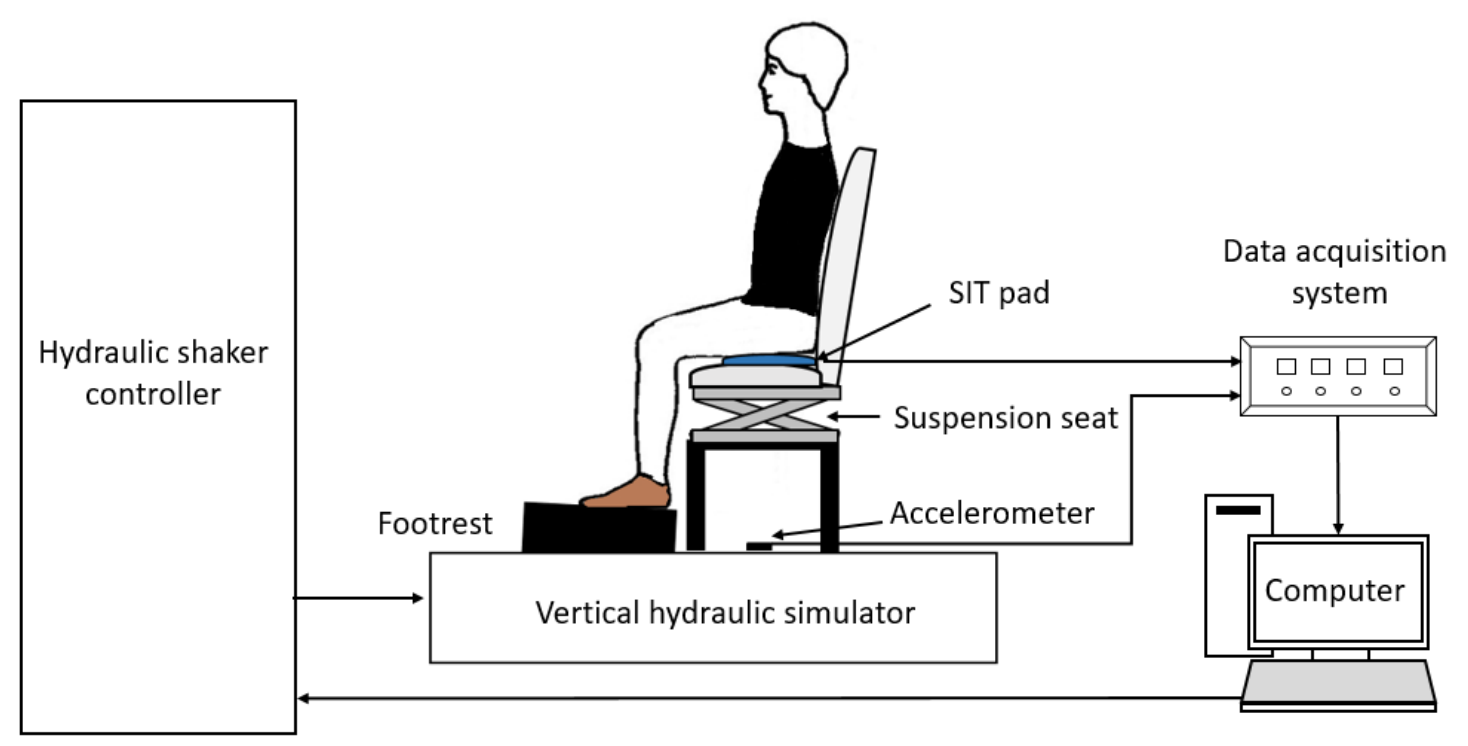

Figure 1. Schematic diagram of the experimental setup.

\section{Model Description}

Figure 2 shows a three-degree-of-freedom lumped parameter model to predict suspension seat transmissibility. The model has three parallel mass-spring-damper systems. Each of the subsystems represents the human body, seat cushion and suspension seat.

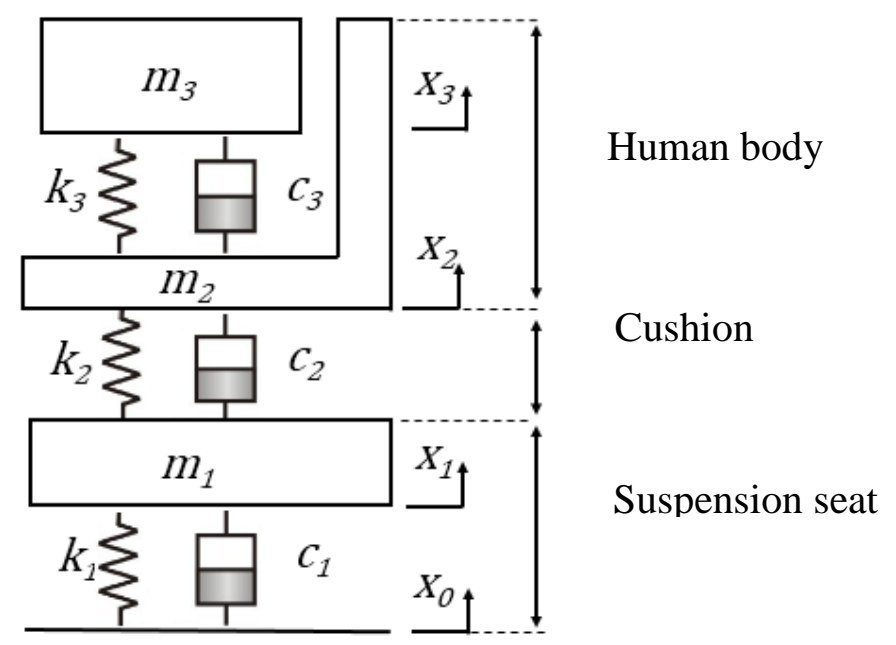

Figure 2. Three-degree-of-freedom lumped parameter model.

where:

$m_{1}, k_{1}$ and $c_{1} \quad: \quad m_{1}, k_{1}$ and $c_{1}$ are the mass, stiffness coefficient and damping coefficient of subsystem 1.

$m_{2}, k_{2}$ and $c_{2} \quad: \quad m_{2}, k_{2}$ and $c_{2}$ are the mass, stiffness coefficient and damping coefficient of subsystem 2 
$m_{3}, k_{3}$ and $c_{3} \quad: \quad m_{3}, k_{3}$ and $c_{3}$ are the mass, stiffness coefficient and damping coefficient of subsystem 3

The equations of motion (EOM) are:

$$
\begin{aligned}
& \mathrm{m}_{1} \ddot{\mathrm{x}}_{1}+\mathrm{c}_{1}\left(\dot{\mathrm{x}}_{1}-\dot{\mathrm{x}}_{0}\right)+\mathrm{k}_{1}\left(\mathrm{x}_{1}-\mathrm{x}_{0}\right)+\mathrm{c}_{2}\left(\dot{\mathrm{x}}_{1}-\dot{\mathrm{x}}_{2}\right)+\mathrm{k}_{2}\left(\mathrm{x}_{1}-\mathrm{x}_{2}\right)=0 \\
& \mathrm{~m}_{2} \ddot{\mathrm{x}}_{2}+\mathrm{c}_{2}\left(\dot{\mathrm{x}}_{2}-\dot{\mathrm{x}}_{1}\right)+\mathrm{k}_{2}\left(\mathrm{x}_{2}-\mathrm{x}_{1}\right)+\mathrm{c}_{3}\left(\dot{\mathrm{x}}_{2}-\dot{\mathrm{x}}_{3}\right)+\mathrm{k}_{3}\left(\mathrm{x}_{2}-\mathrm{x}_{3}\right)=0 \\
& \mathrm{~m}_{3} \ddot{\mathrm{x}}_{3}+\mathrm{c}_{3}\left(\dot{\mathrm{x}}_{3}-\dot{\mathrm{x}}_{2}\right)+\mathrm{k}_{3}\left(\mathrm{x}_{3}-\mathrm{x}_{2}\right)=0
\end{aligned}
$$

Replacing the EOM by applying the Laplace Transform $\left(x \rightarrow X, \dot{x} \rightarrow s X, \ddot{x} \rightarrow s^{2} X\right)$,

$$
\begin{aligned}
& \left(\mathrm{m}_{1} \mathrm{~s}^{2}+\mathrm{c}_{1} \mathrm{~s}+\mathrm{c}_{2} \mathrm{~s}+\mathrm{k}_{1}+\mathrm{k}_{2}\right) \mathrm{X}_{1}(\mathrm{~s})-\left(\mathrm{c}_{1} \mathrm{~s}+\mathrm{k}_{1}\right) \mathrm{X}_{0}(\mathrm{~s})-\left(\mathrm{c}_{2} \mathrm{~s}+\mathrm{k}_{2}\right) \mathrm{X}_{2}(\mathrm{~s})=0 \\
& \left(\mathrm{~m}_{2} \mathrm{~s}^{2}+\mathrm{c}_{2} \mathrm{~s}+\mathrm{c}_{3} \mathrm{~s}+\mathrm{k}_{2}+\mathrm{k}_{3}\right) \mathrm{X}_{2}(\mathrm{~s})-\left(\mathrm{c}_{2} \mathrm{~s}+\mathrm{k}_{2}\right) \mathrm{X}_{1}(\mathrm{~s})-\left(\mathrm{c}_{3} \mathrm{~s}+\mathrm{k}_{3}\right) \mathrm{X}_{3}(\mathrm{~s})=0 \\
& \left(\mathrm{~m}_{3} \mathrm{~s}^{2}+\mathrm{c}_{3} \mathrm{~s}+\mathrm{k}_{3}\right) \mathrm{X}_{3}(\mathrm{~s})-\left(\mathrm{c}_{3} \mathrm{~s}+\mathrm{k}_{3}\right) \mathrm{X}_{2}(\mathrm{~s})=0
\end{aligned}
$$

For simplification, the equation can be expressed as:

$$
\begin{aligned}
& \mathrm{AX}_{1}(\mathrm{~s})-\mathrm{BX}_{0}(\mathrm{~s})-\mathrm{CX}_{2}(\mathrm{~s})=0 \\
& \mathrm{DX}_{2}(\mathrm{~s})-\mathrm{CX}_{1}(\mathrm{~s})-\mathrm{EX}_{3}(\mathrm{~s})=0 \\
& \mathrm{FX}_{3}(\mathrm{~s})-\mathrm{EX}_{2}(\mathrm{~s})=0
\end{aligned}
$$

Where:

$\mathrm{A}=\mathrm{m}_{1} \mathrm{~s}^{2}+\mathrm{c}_{1} \mathrm{~s}+\mathrm{c}_{2} \mathrm{~s}+\mathrm{k}_{1}+\mathrm{k}_{2}, \mathrm{~B}=\mathrm{c}_{1} \mathrm{~s}+\mathrm{k}_{1}, \mathrm{C}=\mathrm{c}_{2} \mathrm{~s}+\mathrm{k}_{2}, \mathrm{D}=\mathrm{m}_{2} \mathrm{~s}^{2}+\mathrm{c}_{2} \mathrm{~s}+\mathrm{c}_{3} \mathrm{~s}+\mathrm{k}_{2}+\mathrm{k}_{3}$, $\mathrm{E}=\mathrm{c}_{3} \mathrm{~s}+\mathrm{k}_{3}$ and $\mathrm{F}=\mathrm{m}_{3} \mathrm{~s}^{2}+\mathrm{c}_{3} \mathrm{~s}+\mathrm{k}_{3}$

By mathematical manipulation, the seat transmissibility, $T(s)$ of the model can be calculated as:

$$
\mathrm{T}(\mathrm{s})=\mathrm{X}_{2} / \mathrm{X}_{0}=\frac{\mathrm{B}}{\frac{\mathrm{AD}-\mathrm{AE}^{2} / \mathrm{F}}{\mathrm{C}}-\mathrm{C}}
$$

The seat transmissibility modulus $(|T|)$ and the phase $\left(\arctan ^{-1}\right)$ can be determined by calculating the real and imaginary parts of the seat transmissibility.

$$
|\mathrm{T}|(\omega)=\left((\operatorname{ReT}(\omega))^{2}+(\operatorname{ImT}(\omega))^{2}\right)^{1 / 2}
$$

Phase $\mathrm{T}(\omega)=\tan ^{-1}\left(\frac{\operatorname{ImT}(\omega)}{\operatorname{ReT}(\omega)}\right)$

\section{RESULTS AND DISCUSSION}

\section{Fitting the Model with the Experimental Data}


The optimised model parameters were determined by a curve fitted to the experimental data obtained by Qiu [19]. The minimum constrained value function was obtained from the optimisation toolbox (fmincon ()) of MATLAB (R2017a).

The model parameters were refined to minimise the error, as below:

$$
\text { error }=\mathrm{w}_{1} \sum_{\mathrm{i}=1}^{\mathrm{N}}\left(\mathrm{T}_{\mathrm{m}}(\mathrm{i})-\mathrm{T}_{\mathrm{e}}(\mathrm{i})\right)^{2}+\mathrm{w}_{2} \sum_{\mathrm{i}=1}^{\mathrm{N}}\left(\mathrm{P}_{\mathrm{m}}(\mathrm{i})-\mathrm{P}_{\mathrm{e}}(\mathrm{i})\right)^{2}
$$

where:

$\mathrm{T}_{\mathrm{m}}(\mathrm{i})$ and $\mathrm{P}_{\mathrm{m}}(\mathrm{i})$ : $\quad$ The seat transmissibility modulus and phase of the model

$\mathrm{T}_{\mathrm{e}}(\mathrm{i})$ and $\mathrm{P}_{\mathrm{e}}(\mathrm{i})$ : $\quad$ The seat transmissibility modulus and phase of the experimental data

$\mathrm{w}_{1}$ and $\mathrm{w}_{2} \quad$ : The weighting factors to improve the fitting

All model parameters were assigned an initial guess, based on previous reported literature, which was corrected during the optimisation process. The model parameters for human subjects are based on basic parameters of the seated human body [20]. In order to simulate the boundary conditions and ranges for seated vehicle operators, the weight of the human body was set to be $73 \%$ of its total weight, resulted in the range of $40-80$ $\mathrm{kg}$ (representing light to heavy subjects) $[18,21]$.

According to the parameters from previous anthropometry and experimental data, the body parts stiffness is classified within the range of $100-300,000 \mathrm{Nm}^{-1}[22,23]$, and the human body parts damping is recommended within the range of $500-4,000 \mathrm{Nsm}^{-1}$ $[22,24]$. The boundary conditions for optimisation of the human body is expressed as:

$$
\begin{aligned}
& 40 \mathrm{~kg} \\
& 100 \mathrm{Nm}^{-1} \leq \mathrm{m}_{3} \leq 80 \mathrm{~kg} \\
& 500 \mathrm{ksm}_{3} \leq 300,000 \mathrm{Nm}^{-1} \\
& \mathrm{c}_{3} \leq 4,000 \mathrm{Nsm}^{-1}
\end{aligned}
$$

The optimisation process by using the curve fitting method of the median seat transmissibility modulus and phase is shown in Figure 3. The developed seat transmissibility model in this study provides a good fit at the first peak of resonance frequency. Nevertheless, the model does not reflect at the second peak of the resonance frequency.

The proposed model used one degree-of-freedom to represent a human response. The previous study suggested that two, three and four degree-of-freedom to represent the biodynamic response of the human body [25-31]. Although the reported models provide a good fit at first and second resonance of the apparent mass, this is not the case for the second resonance of the seat transmissibility. Thus, the simplified model proposed in this study is enough, as it provides a reasonable fit for the primary resonance of the modulus and phase of suspension seat transmissibility. 

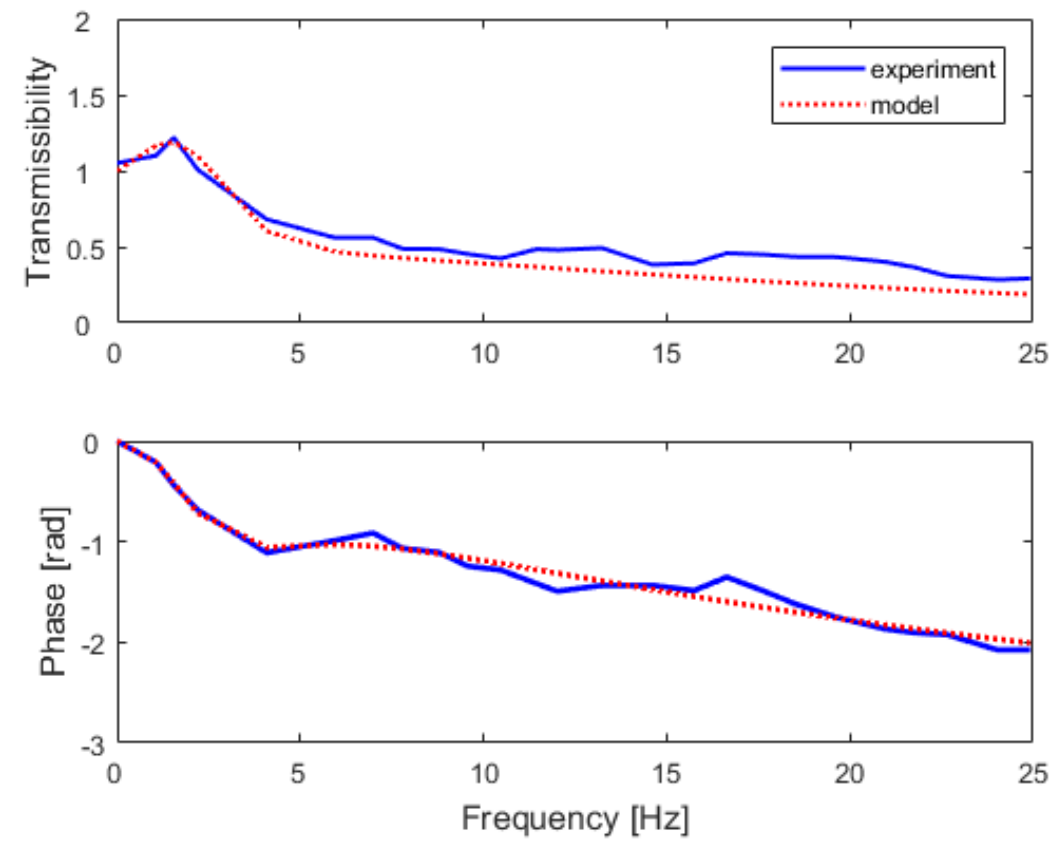

Figure 3. Median seat transmissibility modulus and phase of both of the experimental and optimised model measured at $1.0 \mathrm{~m} / \mathrm{s}^{2}$ r.m.s.

Figure 4 shows the curve fitting according to the weight categories. Three categories of weight were tested in this study (light to heavy subjects). Note that as the subject weight increases, the model parameters of the suspension system changes as well. This condition suggests that the isolation system properties will adjust to compensate with the weight changes. By increasing the subject's weight, the primary resonance peak is reduced and shifted to a lower frequency. This is well predicted by the proposed model.
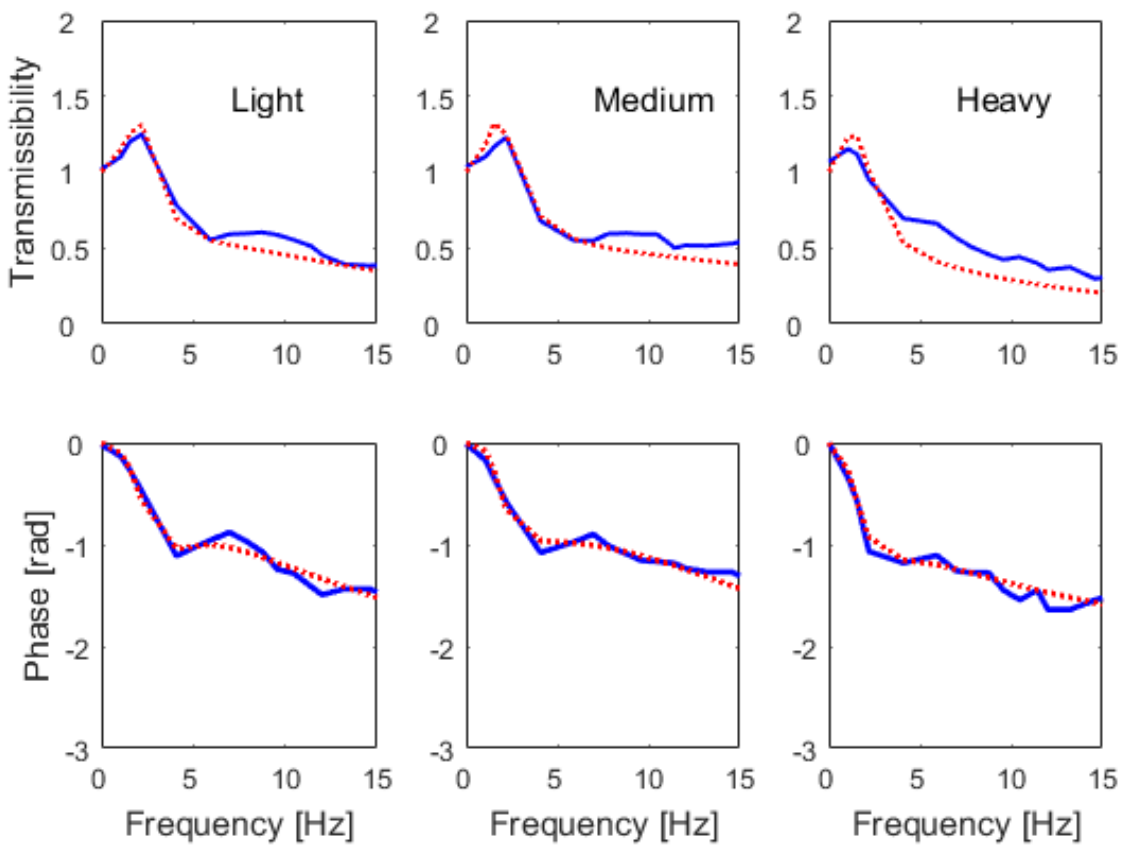

Figure 4. Seat transmissibility modulus and phase of both of the experimental and optimised model with three categories at $1.0 \mathrm{~m} / \mathrm{s}^{2}$ r.m.s. 
All the optimised model parameters were demonstrated in Table 1. Parameters variability are observed involving different weight categories. Further discussion about the variability of the parameters is discussed in the sensitivity analysis.

Table 1. Optimised model parameters.

\begin{tabular}{lccccccccc}
\hline Subject & $\mathrm{m}_{1}$ & $\mathrm{~m}_{2}$ & $\mathrm{~m}_{3}$ & $\mathrm{k}_{1}$ & $\mathrm{k}_{2}$ & $\mathrm{k}_{3}$ & $\mathrm{c}_{1}$ & $\mathrm{c}_{2}$ & $\mathrm{c}_{3}$ \\
& $(\mathrm{~kg})$ & $(\mathrm{kg})$ & $(\mathrm{kg})$ & $(\mathrm{N} / \mathrm{m})$ & $(\mathrm{N} / \mathrm{m})$ & $(\mathrm{N} / \mathrm{m})$ & $(\mathrm{Ns} / \mathrm{m})$ & $(\mathrm{Ns} / \mathrm{m})$ & $(\mathrm{Ns} / \mathrm{m})$ \\
\hline Light & 11 & 6 & 40 & 15,473 & 44,229 & 22,283 & 2,267 & 215 & 969 \\
Medium & 9 & 7 & 56 & 22,302 & 100,000 & 21,439 & 2,074 & 210 & 1,666 \\
Heavy & 10 & 6 & 75 & 9,879 & 50,037 & 33,393 & 1,815 & 200 & 2,166 \\
\hline
\end{tabular}

\section{Sensitivity analysis}

Sensitivity analysis was performed on the median data (refer to Table 2) of the suspension seat transmissibility. The analysis was conducted by varying model parameters one at a time by $\pm 50 \%$ from the optimised value of mass ( $m_{1}, m_{2}$ and $\left.m_{3}\right)$, stiffness $\left(k_{1}, k_{2}\right.$ and $\left.k_{3}\right)$, and damping $\left(c_{1}, c_{2}\right.$ and $\left.c_{3}\right)$ coefficients for all the subsystems. The test was carried out to determine the influence of each parameter to the peak of the resonance frequency. The variation by $\pm 50 \%$ of each parameter allowed us to find the key parameters that affect the suspension seat transmissibility, as shown in Figure 5.

Table 2: Optimised median model parameters

\begin{tabular}{cccccccccc}
\hline & $\begin{array}{c}\mathrm{m}_{1} \\
(\mathrm{~kg})\end{array}$ & $\begin{array}{c}\mathrm{m}_{2} \\
(\mathrm{~kg})\end{array}$ & $\begin{array}{c}\mathrm{m}_{3} \\
(\mathrm{~kg})\end{array}$ & $\begin{array}{c}\mathrm{k}_{1} \\
(\mathrm{~N} / \mathrm{m})\end{array}$ & $\begin{array}{c}\mathrm{k}_{2} \\
(\mathrm{~N} / \mathrm{m})\end{array}$ & $\begin{array}{c}\mathrm{k}_{3} \\
(\mathrm{~N} / \mathrm{m})\end{array}$ & $\begin{array}{c}\mathrm{c}_{1} \\
(\mathrm{Ns} / \mathrm{m})\end{array}$ & $\begin{array}{c}\mathrm{c}_{2} \\
(\mathrm{Ns} / \mathrm{m})\end{array}$ & $\begin{array}{c}\mathrm{c}_{3} \\
(\mathrm{Ns} / \mathrm{m})\end{array}$ \\
\hline Median & 10 & 6 & 56 & 15,473 & 50,037 & 22,283 & 2,074 & 210 & 1,666 \\
\hline
\end{tabular}

At low frequencies, the mass of the human subject, $m_{3}$ shows the noticeable effect on the response of seat transmissibility. Not much change can be observed when varying the mass of the suspension seat and its cushion. Changes of mass for the suspension system do not affect the suspension seat transmissibility. Varying the spring stiffness resulted in changes in the primary resonance frequency for all the subsystems. Nevertheless, only $k_{2}$ shows divergence after the first peak. Note that the first peak is shifting as we vary the damping properties at the frequency of less than $5 \mathrm{~Hz}$ for $c_{1}$. The human body damping properties, represented by $c_{3}$ shows divergence at the frequency more than $5 \mathrm{~Hz}$.

From the sensitivity analysis, it was found that seat transmissibility was most sensitive to the stiffness and damping of the suspension seat and the mass of the human body. It is observed that not only the suspension seat contributed to the first peak of the resonance frequency, but the human body as well. The dynamic properties of the human body affect the dynamic properties of the suspension seat, and vice versa. Thus, it is necessary to incorporate the human body properties into the model. For simplicity, this proposed model is sufficient to represent the suspension seat-person to predict the suspension seat's transmissibility. 

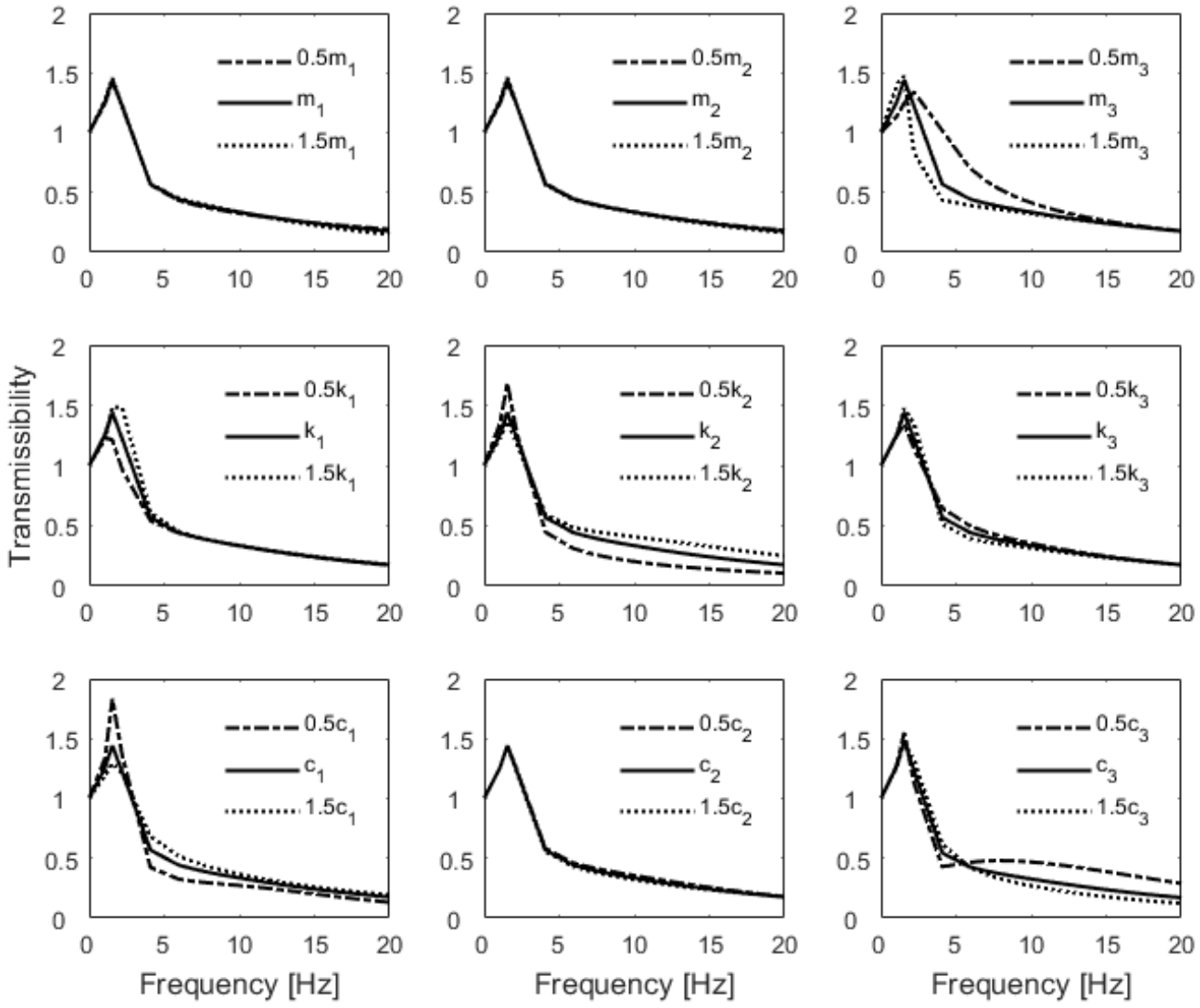

Figure 5. Sensitivity analysis of the seat transmissibility parameters by varying $\pm 50 \%$ of the optimised value.

\section{CONCLUSION}

A three-degree-of-freedom lumped parameter has been developed to predict seat transmissibility of suspension seats used on off-road conditions. The model provides a close fit to the first peak of resonance frequency in predicting the seat transmissibility. The model suggests that the human body, when integrated with the suspension seat, forms a coupled system that contributes to the dynamic characteristics of the suspension system. In addition, The mass of a human subject can affect the isolation properties of the suspension seat at low frequencies. The lumped parameter model provides advantages in the sense of allowing the seat's dynamic characteristics to be represented as stiffness and damping, which are robust enough to be used for different types of seats. This study provides helpful guidelines to seat manufacturers in predicting seat transmissibility and improving the seat design, especially on the off-road conditions.

\section{ACKNOWLEDGEMENT}

The authors would like to acknowledge the Fundamental Research Grant Scheme (FRGS vote no 5524500) and Universiti Putra Malaysia (GP-IPS) for providing financial supports for the study. 


\section{REFERENCES}

[1] Ismail AR, Abdullah SNA, Abdullah AA, Deros BM. A descriptive analysis of factors contributing to bus drivers' performances while driving: A case study in Malaysia. International Journal of Automotive and Mechanical Engineering 2015; 11: 2430-37.

[2] Nuawi MZ, Ismail AR, Nor MJM, Rahman MM. A comparative study of wholebody vibration exposure in train and car passengers: A case study in Malaysia. International Journal of Automotive and Mechanical Engineering 2011; 4: 490503.

[3] Reza-Kashyzadeh K, Ostad-Ahmad-Ghorabi MJ, Arghavan A. Investigating the effect of road roughness on automotive component. Engineering Failure Analysis 2014; 41(3): 96-107.

[4] Lo L, Fard M, Subic A, Jazar R. Structural dynamic characterization of a vehicle seat coupled with human occupant. Journal of Sound and Vibration 2013; 332: 1141-52.

[5] Kim E, Fard M, Kato K. Characterisation of the human-seat coupling in response to vibration. Ergonomics 2017; 60(8): 1085-100.

[6] Danko J, Milesich T, Bucha J. Nonlinear model of the passenger car seat suspension system. Journal of Mechanical Engineering 2017; 67(1): 23-8.

[7] Yan Z, Zhu B, Li X, Wang G. Modeling and analysis of static and dynamic characteristics of nonlinear seat suspension for off-road vehicles. Shock and Vibration 2015; Article ID 938205: 1-13.

[8] Wei L, Griffin MJ. The prediction of seat transmissibility from measures of seat impedance. Journal of Sound and Vibration 1998b; 214: 121-37.

[9] Liang CC, Chiang CF. Modelling of a seated human body exposed to vertical vibrations in various automotive postures. Industrial Health 2008; 46: 125-37.

[10] Chi L, Qiu Y, Griffin MJ. Finite element modelling of human-seat interactions: vertical in-line and fore-and-aft cross-axis apparent mass when sitting on a rigid seat without backrest and exposed to vertical vibration. Ergonomics 2015; 58(7): 1-13.

[11] Qiu Y, Griffin MJ. Modelling the fore-aft apparent mass of the human body and the transmissibility of seat backrests. Vehicle System Dynamics 2011; 49(5):70322.

[12] Gunston TP, Rebelleb J, Griffin MJ. A comparison of two methods of simulating seat suspension dynamic performance. Journal of Sound and Vibration 2004; 278: 117-34.

[13] Stein GJ, Mucka P, Gunston T, Badura S. Modelling and simulation of locomotive driver's seat vertical suspension vibration isolation system. International Journal of Industrial Ergonomics 2008; 38: 384-95.

[14] International Organization for Standardization, 2001. Mechanical vibration and shock - Range of idealized values to characterize seated-body biodynamic response under vertical vibration. ISO 5982: 2001.

[15] Deutsches Institut für Normierung e.V, 2003. Mechanical impedance at the driving point and transfer functions of the human body. DIN 45676: 2003.

[16] Zhang X, Qiu Y, Griffin MJ. Developing a finite element model of a car seat with occupant for predicting vibration transmissibility in the vertical direction. Ergonomics 2015; 58(7): 1220-31. 
[17] Siefert A, Pankoke S, Wolfel HP. Virtual optimization car passenger seats: simulation of static dynamic effects on drivers' seating comfort. International Journal of Industrial Ergonomics 2008; 38(5-6): 410-24.

[18] International Organization for Standardization, 2000. Earth-moving machineryLaboratory evaluation of operator seat vibration. ISO 7096: 2000.

[19] Qiu Y. Dynamic Characteristics of a suspension seat determined in laboratory study. Journal of Ergonomics 2017; 7(6): 220.

[20] Pheasant S, Haslegrave CM. Bodyspace: Anthropometry, ergonomics and the design of work. 3rd Edition. Boca Raton: CRC Press; 2005.

[21] International Organization for Standardization, 2003. Agricultural wheeled tractors- Laboratory measurement of transmitted vibration. ISO 5007: 2003.

[22] Bai XX, Xu SX, Cheng W, Qian LJ. On 4-degree-of-freedom biodynamic models of seated occupants: Lumped-parameter modeling. Journal of Sound and Vibration 2017; 402: 122-41.

[23] Kazarian L.Dynamic response characteristics of the human vertebral column: An experimental study on human autopsy specimens. Acta Orthopaedica Scandinavica 1972; 43:1-188.

[24] Mertens H. Nonlinear behavior of sitting humans under increasing gravity, Aviation Space Environmental Medicine 1978; 49: 287-98.

[25] Gan Z, Hillis AJ, Darling J. Biodynamic modelling of seated human subjects exposed to uncoupled vertical and fore-and-aft whole-body vibration. Journal of Vibration Engineering and Technologies 2015; 301-14.

[26] Wang Y, Rahmatalla S. Human head-neck models in whole-body vibration: effect of posture. Journal Biomechanic 2013; 46: 702-10.

[27] Gao JH, Hou ZC, He L, Xia QS. Vertical vibration characteristics of seated human bodies and a biodynamic model with two degrees of freedom. Science China Technology 2011; 54: 2776-84.

[28] Hou ZC, Gao JH, He L. Vertical vibration characteristics of seated human bodies and the parameters of a biodynamic model with three degrees of freedom. Journal Harbin Engineering University 2011, 32:1223-27.

[29] Wan Y, Schimmels JM, A simple model that captures the essential dynamics of a seated human exposed to whole body vibration. Advances in Bioengineering, ASME 1995; 31: 333-34.

[30] Tufano S, Griffin MJ. Nonlinearity in the vertical transmissibility of seating: the role of the human body apparent mass and seat dynamic stiffness. Vehicle System Dynamics 2012; 51: 122-38.

[31] Nawayseh N. A mathematical model of the apparent mass of the human body under fore-and-aft whole-body vibration. International Journal of Automotive and Mechanical Engineering 2016; 13(3): 3613 - 27. 